\title{
Promoting neuroregeneration after perinatal arterial ischemic stroke: neurotrophic factors and mesenchymal stem cells
}

\author{
Nienke Wagenaar ${ }^{1}$, Caroline G M de Theije ${ }^{2}$, Linda S de Vries ${ }^{1}$, Floris Groenendaal ${ }^{1}$, Manon J N L Benders ${ }^{1,3}$ and \\ Cora H A Nijboer ${ }^{2,3}$
}

Newborns suffering from perinatal arterial ischemic stroke (PAIS) are at risk of neurodevelopmental problems. Current treatment options for PAIS are limited and mainly focus on supportive care, as presentation of PAIS is beyond the time window of current treatment strategies. Therefore, recent focus has shifted to interventions that stimulate regeneration of damaged brain tissue. From animal models, it is known that the brain increases its neurogenic capability after ischemic injury, by promoting neural cell proliferation and differentiation. However, neurogenesis is not maintained at the long term, which consequently impedes full repair leading to adverse consequences later in life. Boosting neuroregeneration of the newborn brain using treatment with neurotrophic factors and/or mesenchymal stem cells (MSCs) may be promising novel therapeutic strategies to improve neurological prospects and quality of life of infants with PAIS. This review focuses on effectiveness of neurotrophic growth factors, including erythropoietin, brain-derived neurotrophic factor, vascular endothelial growth factor, glial-derived neurotrophic factor, and MSC therapy, in both experimental neonatal stroke studies and first clinical trials for neonatal ischemic brain injury.

$\mathbf{P}$ erinatal arterial ischemic stroke (PAIS) is an important cause of perinatal morbidity. It occurs in 1 in 2,500-4,000 live births, forming a large burden for patients and society worldwide $(1,2)$. PAIS manifests itself most often with onesided seizures in the first week after birth, often accompanied with (asymmetric) hypotonia, lethargy, and apnea $(1,3,4)$. Using neuro-imaging, it is commonly identified as a focal wedge-shaped cerebral lesion that leads to loss of all cell types in that part of the brain. PAIS is most often detected in the middle cerebral artery (MCA) with a predilection for the left MCA (3-5). The exact underlying pathology is unknown, but the most important risk factors are intrapartum or peripartum complications, such as prolonged rupture of membranes, thick meconium, and abnormal cardiotocography (6). In
$50-75 \%$ of infants, neonatal stroke leads to abnormal motor and neurodevelopmental outcome, including cerebral palsy, cognitive dysfunction, behavioral disorders, and epilepsy (5). Current treatment options for PAIS mainly focus on supportive care, such as controlling hypoglycemia and treatment of (subclinical) seizures. As these treatments offer limited protection, additional therapeutic strategies for PAIS are urgently needed. Early neuroprotective treatments mainly aim at preventing production of free radicals and apoptotic cell death. For example, therapeutic hypothermia, started early after birth, has shown benefit in newborns with hypoxic-ischemic (HI) encephalopathy (HIE) (7). However, hypothermia is only beneficial when applied within $6 \mathrm{~h}$ after a well-documented HI insult followed by moderate-to-severe encephalopathy (8). As cerebral abnormalities evoked by PAIS often do not present themselves within this short therapeutic timeframe, these neuroprotective treatment strategies are not applicable to PAIS. Owing to the relative late diagnosis, therapeutic focus has rather shifted to interventions that stimulate repair of the damaged newborn brain (9). In most recent years, preclinical research has aimed to develop additional therapies that boost endogenous regenerative pathways, as these will be critical for improving outcome in severely affected PAIS patients.

\section{NEUROREGENERATION}

Neural stem cells (NSCs) residing in the subventricular zone and subgranular zone of the hippocampus are self-renewing and are capable of differentiating into neurons, astrocytes, and oligodendrocytes. These processes of neurogenesis and gliogenesis continue throughout life but decrease with age. After (hypoxic) ischemic brain injury, the brain enhances its neurogenic capability by promoting proliferation of young precursors not only in the subventricular zone and subgranular zone but also in the striatum, cortex, and hippocampus $(10,11)$. Growth factors, which regulate several cellular processes including apoptosis, inflammation, angiogenesis, cell differentiation, and proliferation, are increasingly expressed following exposure to $\mathrm{HI}$ and thereby aid in

${ }^{1}$ Department of Neonatology, Wilhelmina Children's Hospital, University Medical Centre Utrecht, Utrecht University, Utrecht, The Netherlands; ${ }^{2}$ Laboratory of

Neurolmmunology and Developmental Origins of Disease, University Medical Centre Utrecht, Utrecht University, Utrecht, The Netherlands. Correspondence: Cora H.A. Nijboer (c.nijboer@umcutrecht.nl)

${ }^{3}$ The last two authors contributed equally to this work.

Received 23 June 2017; accepted 19 September 2017; advance online publication 1 November 2017. doi:10.1038/pr.2017.243 
Table 1. Neurotrophic factor therapy in animal models of neonatal stroke

\begin{tabular}{|c|c|c|c|c|c|}
\hline Paper & $\begin{array}{l}\text { Growth } \\
\text { Factor }\end{array}$ & $\begin{array}{l}\text { Animal } \\
\text { model }\end{array}$ & $\begin{array}{l}\text { Type of ischemic } \\
\text { injury }\end{array}$ & Dosing and timing of treatment & Administration route \\
\hline $\begin{array}{l}\text { Dixon and Sherrard } \\
(40)\end{array}$ & BDNF & $\begin{array}{l}\text { Neonatal rat: } \\
\text { P15 or P30 }\end{array}$ & $\begin{array}{l}\text { Unilateral transection } \\
\text { of olivocerebellar } \\
\text { pathways }\end{array}$ & $\begin{array}{c}1 \text { dose of } 1 \mu \mathrm{l} \text { of rh-BDNF }(4 \mu \mathrm{mol} / \mathrm{l}) \text { at } \\
24 \mathrm{~h} \text { after injury }\end{array}$ & Intracerebellar injection \\
\hline Husson et al. (42) & BDNF & $\begin{array}{l}\text { Neonatal } \\
\text { mouse: P5 }\end{array}$ & $\begin{array}{c}\text { Focal excitotoxic } \\
\text { lesions: periventricular } \\
\text { leukomalacia }\end{array}$ & $\begin{array}{l}1 \text { dose of } 0.5,5 \text {, or } 50 \mathrm{ng} \text { rh-BDNF } \\
\text { simultaneously with excitotoxic drugs }\end{array}$ & Intracerebral (intraparenchymal) \\
\hline
\end{tabular}

\begin{tabular}{|c|c|c|c|c|}
\hline $\begin{array}{l}\text { Bemelmans et al. } \\
\text { (127) }\end{array}$ & BDNF & $\begin{array}{l}\text { Neonatal } \\
\text { mouse: P5 }\end{array}$ & $\begin{array}{l}\text { Focal excitotoxic } \\
\text { lesions: periventricular } \\
\text { leukomalacia }\end{array}$ & $\begin{array}{c}1 \text { dose of } 10 \mathrm{ng} \text { or } 25 \mathrm{ng} \text { of LV-BDNF } \\
\text { (with BDNF level reaching } 0.086- \\
0.118 \mathrm{pg} / \mathrm{mg} \text { protein) } 3 \text { days before } \\
\text { inducing lesions (P2) }\end{array}$ \\
\hline Sola et al. (26) & EPO & $\begin{array}{l}\text { Neonatal rat: } \\
\quad \text { P7 }\end{array}$ & Permanent MCAO & $\begin{array}{l}1 \text { dose of } 1,000 \mathrm{U} / \mathrm{kg} \text { rh-EPO at } 15 \mathrm{~min} \\
\text { after injury and } 2 \text { doses of } 100,1,000 \text {, }\end{array}$ \\
\hline
\end{tabular}

Intraventricular delivery of BDNFexpressing lentiviral vector

Chang et al. (2)

EPO

Neonatal rat: P10

Gonzalez et al. (27)

Gonzalez et al. (28)

Transient MCAO: $180 \mathrm{~min}$

\section{Neonatal rat:} P7

Dzietko et al. (51)

Transient MCAO:
Transient MCAO: $45 \mathrm{~min}$

\section{Transient MCAO:}

45 min

1 dose of $5 \mathrm{U} / \mathrm{g}$ rh-EPO immediately upon reperfusion

1 dose of $5 \mathrm{U} / \mathrm{g}$ rh-EPO immediately upon reperfusion

1 dose of $5 \mathrm{U} / \mathrm{g}$ rh-EPO immediately upon reperfusion or 1 dose of $1 \mathrm{U} / \mathrm{g}$ immediately upon reperfusion

followed by $1 \mathrm{U} / \mathrm{g}$ at $24 \mathrm{~h}$ and 7 days after injury

3 doses of rh-EPO 1,000 U/kg started one week after injury

3 doses of rh-EPO 1,000 U/kg started $15 \mathrm{~min}$. after injury and repeated once a day for 2 days $90 \mathrm{~min}$
1 dose of $1.5 \mu \mathrm{g} / \mathrm{kg}$ rh-VEGF at day 8 after injury (P18)
Intraperitoneal

Effect

BDNF induced axonal growth by transcommissural olivocerebellar reinnervation at 7 days after injury

BDNF reduced $36 \%$ and $60 \%$ of cortical and white matter lesions, involving TrkB receptors, MAPK pathway and reduced apoptosis at $120 \mathrm{~h}$ after injury. At P0, BDNF exacerbated neuronal death. At P10, BDNF did not have an effect

BDNF induced protection against ischemic injury at 5 days after injury. Viral-mediated gene transfer was more efficient for neuroprotection than the intraparenchymal route

EPO reduced the number of apoptotic cells and decreased infarct area and volume at 3 days after injury providing significant neuroprotection. 1,000 U/kg rh-EPO for 3 days was the most effective dose

Intraperitoneal

EPO preserved hemispheric brain volume and improved functional outcome (by decreasing forelimb asymmetry) at 2 weeks after injury

Intraperitoneal

EPO preserved hemispheric brain volume, increased neurogenesis and decreased gliogenesis at 6 weeks after

$$
\text { injury }
$$

Intraperitonea

EPO increased brain volume and improved functional outcome (spatial learning and memory performance) at 2

$$
4 \text { months after MCAO }
$$

Intraperitoneal

Delayed EPO treatment improved histological and functional outcome at 4 weeks after MCAO

Intraperitoneal

EPO reduced infarct volume and improved sensorimotor function recovery at $6-12$ weeks after MCAO. The effect was more beneficial in female compared with male rats

VEGF enhanced angiogenesis, endothelial proliferation, and vessel volume leading to improved brain injury recovery at 1 week after injury 
boosting neurogenesis (12). However, long-term neurogenesis is not maintained after HI brain injury, which consequently impedes full repair. It is therefore crucial to assist the brain during regeneration of injured areas. Stimulation of neurogenesis by exogenous administration of neurotrophic factors has been studied in the context of neonatal brain injury, especially in preclinical research. Furthermore, boosting endogenous neuroregeneration by administration of stem cells has also gained considerable attention in the treatment of neonatal brain injury. Therefore, this review will provide an up-to-date evaluation of preclinical and clinical evidence for potential future neuroregenerative therapies for neonatal stroke comprising neurotrophic factors and stem cells.

\section{ANIMAL MODELS}

When investigating neonatal brain injury, the use of highly reproducible and clinically relevant animal models is crucial. The most commonly used rodent model for neonatal brain injury is the Rice-Vannucci model, which combines permanent unilateral carotid artery ligation with exposure to systemic hypoxia in newborn pups $(13,14)$. This model, however, contains a systemic hypoxic component that better reflects HIE caused by perinatal asphyxia in human neonates rather than PAIS. Therefore, specific models of neonatal stroke have been designed in newborn rodents that use permanent or transient occlusion of the MCA (MCAO) leading to (more) focal ischemia. Studies have shown contrasting variability between $\mathrm{HI}$ and stroke models and also the pathophysiological underlying mechanisms differ between HIE and stroke (15). As this review aims at covering specifically PAIS, the experimental data discussed in this paper will focus on regenerative therapies in animal models of neonatal stroke only.

\section{PROMOTING NEUROREGENERATION: ANIMAL MODELS OF NEONATAL STROKE \\ Erythropoietin}

Erythropoietin (EPO) is originally known for its role in erythropoiesis and it has long been used to treat anemia in premature infants $(16,17)$. However, non-hematopoietic effects of EPO have also been shown. EPO is produced in the developing brain by multiple cell types, including neurons, astrocytes, oligodendrocytes, and microglia, and it promotes growth of the central nervous system $(18,19)$. EPO is upregulated after cerebral injury, a process regulated by transcription factor hypoxia-inducible factor-1, a factor stabilized by hypoxic conditions $(20,21)$. In vitro, EPO has been proven to exert neuroprotection against neuronal injury as it can reduce free radical formation, inflammation, and apoptosis in neuronal cultures (22). In vitro and in vivo studies have demonstrated that EPO not only prevents ischemiainduced cell death (i.e., acts neuroprotective) but also stimulates neuronal differentiation of neural progenitor cells (23-25). Experimental rodent studies using neonatal stroke models have shown that treatment with EPO substantially reduces infarct volume $(26,27)$ as well as improves motor and cognitive function $(28,29)$. A review from our group 
summarized neuroregenerative effects of EPO in neonatal experimental in vivo studies, including MCAO models (30). In general, EPO administration after MCAO in postnatal day (P) 7-10 rat pups was found to improve neurogenesis, as measured by increased brain volume up to $70 \%$ (Table 1) (30). More recently, it was shown that delayed EPO treatment, up to 1 week after the onset of neonatal stroke, improved histological as well as functional outcome, which underlines the involvement of EPO as a trophic factor stimulating neurogenesis (31). Gonzalez et al. (32) also demonstrated that EPO treatment after neonatal stroke in rats stimulated neural progenitor cells' proliferation in the subventricular zone and migration of these progenitors to the site of the injury, again emphasizing the neuroregenerative effects of EPO.

\section{Brain-derived neurotrophic factor}

Brain-derived neurotrophic factor (BDNF) is a neurotrophic factor known to promote neural cell proliferation and survival in the developing human brain $(33,34)$. BDNF protein expression is especially high in the hippocampus, but BDNF can affect survival and proliferation of several neural cells, including cerebellar and cortical neurons $(33,35)$. The neurogenic effects of BDNF are mediated via activation of two different receptor pathways: the p75 neurotrophin receptor and the tyrosine kinase receptor $\mathrm{B}$, that activates mitogen-activated protein kinase pathways. BDNF levels rapidly increase in response to brain injury in neonatal rats $(36,37)$, leading to reduced neuronal apoptosis and increased neuronal survival (37). In vitro, BDNF improves survival of hypoxic-hypoglycemic hippocampal neurons by reduction of apoptosis through tyrosine kinase receptor B (38). Other in vitro studies demonstrated that $\mathrm{BDNF}$ enhanced neurite outgrowth of neonatal cortical neurons in the presence of astrocytes (39).

To the best of our knowledge, BDNF has never been studied in neonatal rodent models of PAIS. However, in neonatal rat models of focal cerebellar injury, BDNF treatment stimulated axonal regrowth leading to re-innervation of the cerebellum (Table 1) (40). In addition, a neonatal rat model for motorneuron axotomy demonstrated the beneficial effect of $\mathrm{BDNF}$ on motor neuron survival up to 30 days after injury (41). A neonatal mouse model mimicking periventricular leukomalacia in preterm newborns showed that intraparenchymal injections of BDNF (at P5) reduced cortical gray and white matter lesions with $36 \%$ and $60 \%$, respectively. Protective effects of BDNF treatment in this excitotoxic mouse model were associated with tyrosine kinase receptor B receptor/mitogen-activated protein kinase pathway activation and reduced apoptosis (42). However, timing of BDNF administration seemed crucial, as BDNF treatment at P0 exacerbated neuronal death but BDNF treatment at P10 did not have any effects on periventricular leukomalacia in neonatal mice (42). Therefore, more preclinical evidence for beneficial effects of exogenous BDNF administration is needed to determine the exact treatment regimen and possible risks for neonatal stroke.

\section{Vascular endothelial growth factor}

Vascular endothelial growth factor (VEGF) is a factor produced by neurons and astrocytes in the developing brain. Experimental data indicate that VEGF is involved in several stages of neurodevelopment, including migration, differentiation, synaptogenesis, and myelination (43). Furthermore, VEGF stimulates vascular processes such as angiogenesis and vasculogenesis by stimulating endothelial cell proliferation and migration via Flk1 and by improving vascular stabilization via Ang1 (44,45). VEGF also enhances blood-brain barrier maintenance. These vascular processes together contribute to an optimal microenvironment for NSCs to drive neuronal regeneration, thereby demonstrating an important role for VEGF in brain repair $(46,47)$. Experimental studies demonstrate that VEGF expression is increased in the brain after neonatal stroke in vivo (48). Interestingly, increased VEGF expression after neonatal cerebral ischemia is associated with NSC proliferation and differentiation (49). Furthermore, it has been shown that inhibition of the VEGF receptor-2 after neonatal stroke worsened injury, increased cell death, and reduced endothelial cell proliferation in 10day-old rats, indicating a role for VEGF signaling in recovery and repair after ischemic brain injury (50).

Dzietko et al. (51) have shown that intracerebroventricular VEGF treatment enhanced angiogenesis, endothelial proliferation, and vessel volume, leading to improved recovery of brain injury after MCAO in P10 rats (Table 1). Experimental adult stroke models have demonstrated that timing of VEGF administration is crucial: early administration leads to brain edema, whereas late application has desired neuroprotective effects (52). In contrast, in newborn rats with HI early VEGF administration (i.e., at $5 \mathrm{~min}$ to 3 days after injury) resulted in decreased brain damage, possibly via reduced neuronal apoptotic cell death in the cortex and hippocampus $(53,54)$. These studies indicate that in the neonatal brain VEGF does not only support neuroregeneration after brain injury via angiogenesis but may also exert neuroprotective properties by reducing apoptosis via the Akt/extracellular signal-regulated kinase signaling pathway. Overall, late administration of VEGF seems most favorable in neonatal stroke, as diagnosis is usually late after assumed onset of PAIS. However, the exact timing of VEGF for neonatal stroke remains to be studied.

\section{Glial-derived neurotrophic factor}

Glial-derived neurotrophic factor (GDNF) is a member of the transforming growth factor $\beta$ superfamily, produced by glial cells and neurons, and has an important role in neuronal differentiation during normal development (55). In vitro, GDNF was found to increase the number of surviving neonatal rat corticospinal motor neurons (56). After central or peripheral nervous system injury, GDNF also promotes survival and recovery of several types of mature neurons, including motor and dopaminergic neurons $(57,58)$. In neonatal rats with HI brain injury, GDNF levels in the serum and brain were upregulated by $48 \mathrm{~h}$ and returned to normal by 7 days (59). Increased GDNF levels were associated with 


\section{Review | Wagenaar et al.}

reduced neuronal apoptosis, indicating that GDNF may reduce neonatal brain injury (59).

Although GDNF has not been studied in the treatment of neonatal stroke in rodents (Table 1), GDNF treatment induced nearly $100 \%$ neuronal survival of dorsal root ganglions after sciatic nerve axotomy in newborn rats (60). In neonatal rats, GDNF was also found to rescue extraocular motorneurons from axotomy-induced cell death at 30 days after injury (41). To translate GDNF treatment to the clinic for the treatment of PAIS, more preclinical research is needed to overcome several potential hurdles. For example, in contrast to EPO and BDNF, GDNF does not cross the blood-brain barrier, which makes exogenous administration of GDNF more difficult (61). Additionally, GDNF exerts only transient effects, so repeated administration into the cerebral or ventricular space would be required (62).

\section{Mesenchymal stem cell therapy}

Overall, the levels of growth factors that are naturally available during brain development and that are upregulated after an ischemic insult are unable to accomplish full repair of the injured neonatal brain. As described above, boosting neuroregeneration after neonatal brain injury by exogenous administration of single growth factors has been shown to be beneficial in many experimental studies. These factors can stimulate repair of the neonatal brain by promoting neurogenesis and stimulating neural cell survival (Figure 1). Moreover, numerous studies have been performed to explore the potential of multipotent stem cells as a therapy for neonatal brain injury. Experimental data strongly indicate that stem cells secrete a plethora of trophic factors that can boost neuroregenerative processes in the injured neonatal brain.

Multipotent stem cells are capable of self-renewal and can commit to differentiate into cell types of a discrete lineage. For example, hematopoietic stem cells give rise to several blood cell types, such as erythrocytes, lymphocytes, and neutrophils. Other multipotent stem cell types include NSCs and mesenchymal stem cells (MSCs). MSCs can differentiate into cells of the mesoderm, such as bone, cartilage, or fatty tissue, but it has been demonstrated that MSCs are also capable of developing into neuronal cells, given specific conditions (63). MSCs display various characteristics that can be favorable as a regenerative therapy for neonatal brain injury. First, MSCs are found in several birth-related tissues, including the placenta, umbilical cord, and Wharton's Jelly (64). These resources seem ideal for easy and non-invasive isolation of MSCs and allow them to be used in an autologous manner if collected at the time of birth. Moreover, MSCs do not express MHC class II, making them excellent candidates for allogeneic transplantation, as they do not cause immune responses/graft-vs.host disease (65). Given their potent neuroregenerative properties and favorable immunological profile, MSCs seem to be promising for neuroregenerative medicine in neonatal brain injury (64). In animal models of neonatal brain injury, MSC therapy has been shown to improve motor function and cognitive behavior by stimulating neurogenesis, gliogenesis, and axonal remodeling as will be discussed below. Therefore, MSCs could function as miniature factories of a mixture of growth factors to repair neonatal brain injury in a tailormade way.

MSCs have been shown to be effective in repairing brain tissue after neonatal stroke (Table 2). Kim et al. (66) treated P10 rats intracerebroventricularly with umbilical cord-derived MSCs at $6 \mathrm{~h}$ after permanent MCAO. At day 28, they observed that MSC transplantation had significantly attenuated brain infarct volume measured by magnetic resonance imaging and had improved functional motor performance (66). Other studies have focused on non-invasive routes of MSC administration, such as intranasal MSC treatment, which specifically targets the brain (67). It has been shown that MSCs migrate rapidly toward the lesioned brain area, i.e., within $2 \mathrm{~h}$, after intranasal administration $(68,69)$. Wei et al. (70) intranasally administered bone marrow-derived MSCs to $\mathrm{P} 7$ rat pups at $6 \mathrm{~h}$ and 3 days after induction of stroke. At P24, MSC treatment had significantly reduced infarct volume and blood-brain barrier disruption and increased angiogenesis, leading to neurovascular repair and improved cerebral blood flow. MSC treatment also stimulated neurogenesis, leading to better sensorimotor and social functions (70). In addition, van Velthoven et al. $(71,72)$ showed that intranasal MSC treatment at 3 days after neonatal stroke also significantly reduced infarct size and white and gray matter loss in newborn rats, leading to improved motor performance at 28 days after the infarct.

From a mechanistic point of view, it is important to note thatl the number of MSCs at the lesion site drastically decreases at $12 \mathrm{~h}$ after intranasal administration and the majority of cells does not survive $>72 \mathrm{~h}(69,73)$. These findings indicate that the regenerative effects of MSCs in the neonatal brain are not caused by integration of transplanted MSCs themselves but rather by their paracrine effects. It was demonstrated that MSC administration after neonatal HI injury in mice specifically regulates cerebral expression of genes regulating both proliferation and survival (73). In vitro, MSCs that promote axon growth in developing rats were shown to express BDNF and VEGF (74). Furthermore, MSCs that were cultured in the presence of ischemic vs. control brain extracts show a specific upregulation of several growth factors, indicating that MSCs can adapt their secretion profile according to the tissue milieu (75). We hypothesize that the secretion of several neurotrophic factors by MSCs modulates the neurovascular niche to promote endogenous repair of the injured neonatal brain.

\section{ANIMAL MODELS OF ADULT STROKE}

In parallel to neonatal stroke, quite extensive preclinical and clinical research has been performed to study neuroregenerative therapies for the treatment of adult ischemic stroke. It is important to realize that results from adult trials cannot be directly translated to neonatal care for several reasons. First of all, the newborn brain has much greater plastic capacity than the brain of older children and adults. This causes the 


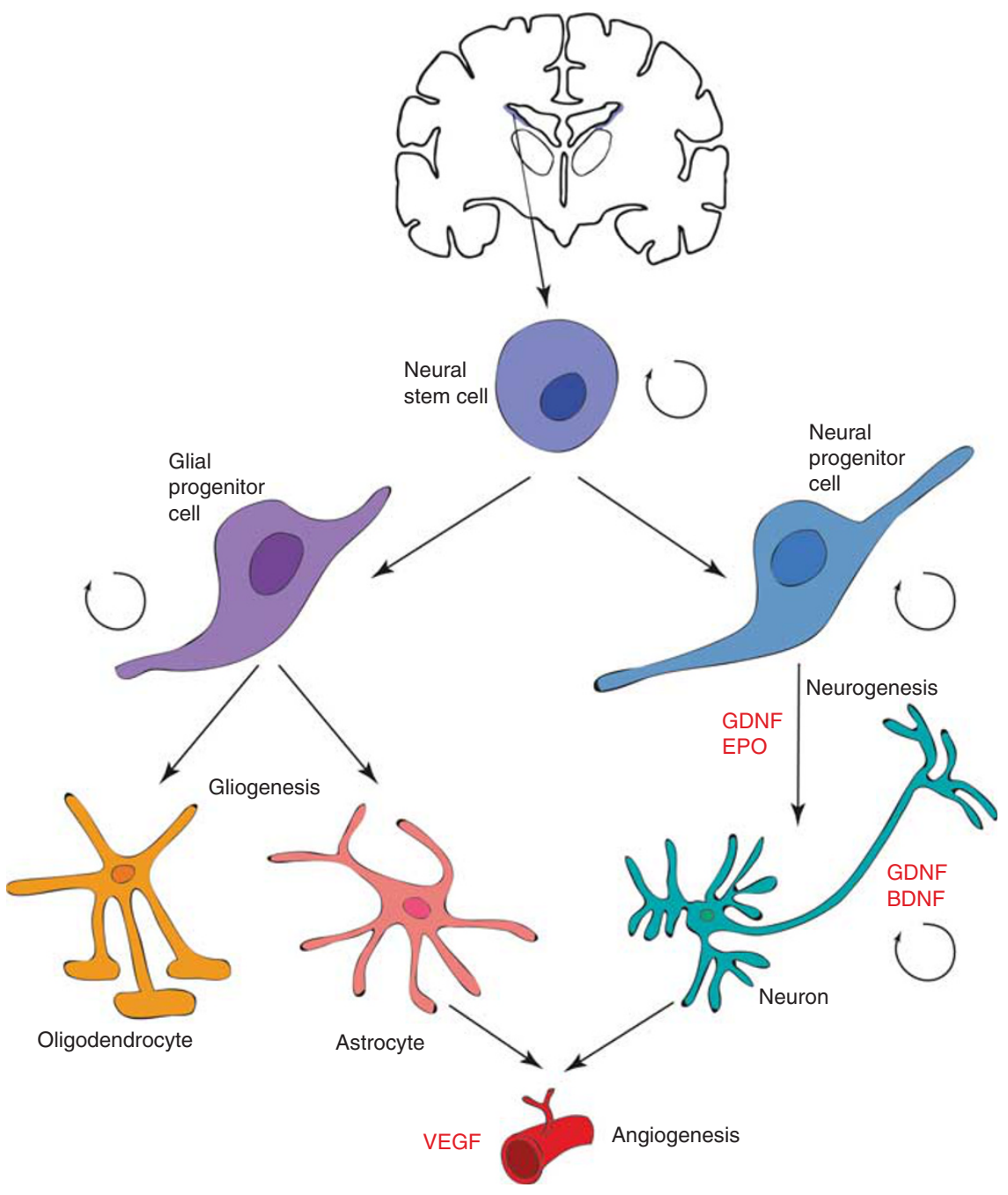

Figure 1. The effects of neurotrophic factors on neurogenesis and gliogenesis. Neural stem cells from the subventricular zone differentiate into two lineages of progenitor cells: glial and neural progenitor cells, resulting in gliogenesis and neurogenesis respectively. Erythropoietin (EPO) stimulates neuronal differentiation of neural progenitor cells. Glial-derived neurotrophic factor (GDNF) is also involved in neurogenesis by increasing the number of neurons but additionally promotes survival and recovery of several types of mature neurons. Brain-derived neurotrophic factor (BDNF) is involved in neural cell proliferation and survival. Vascular endothelial growth factor (VEGF) mainly stimulates vascular processes, such as angiogenesis and vasculogenesis.

newborn to recover relatively more easily after brain injury than an adult (76,77). Second, effectiveness of neuroregenerative treatments reduces with growing age, because endogenous neurogenesis capacity declines with age. In other words, the neonatal brain has more potential to regenerate damaged tissue than the adult brain (78-81). Lastly, PAIS is a different disease than adult stroke, with different pathology and symptomatology (82). Despite these differences, the results from experimental adult stroke studies provide biological plausibility support for potential effectiveness of interventions in PAIS and will therefore be discussed shortly below.

\section{Neurotrophic factors}

Preclinical studies in rodent models of adult stroke have also shown potential effectiveness of administration of the discussed factors EPO, BDNF, VEGF, and GDNF in stroke recovery (83-87). However, neuroregenerative effects of many more (hematopoietic) growth factors, such as granulocyte colonystimulating factor, epidermal growth factor, fibroblast growth factor-2, and insulin-like growth factor were described for adult stroke as well. All these factors are upregulated after focal cerebral ischemia and potentially have a neuroregenerative role by stimulating neurogenesis and angiogenesis and inhibiting neuronal death (88). A review from 2011 provides an overview on experimental studies of acute ischemic stroke in adult rodents using hematopoietic growth factors and neurotrophins. The review summarizes results of studies which demonstrate that these factors both reduce infarct size, brain edema, and apoptosis, as well as stimulate cell proliferation, survival of new mature neurons, and neovessel formation, subsequently leading to improved clinical outcome (88). The authors conclude that 


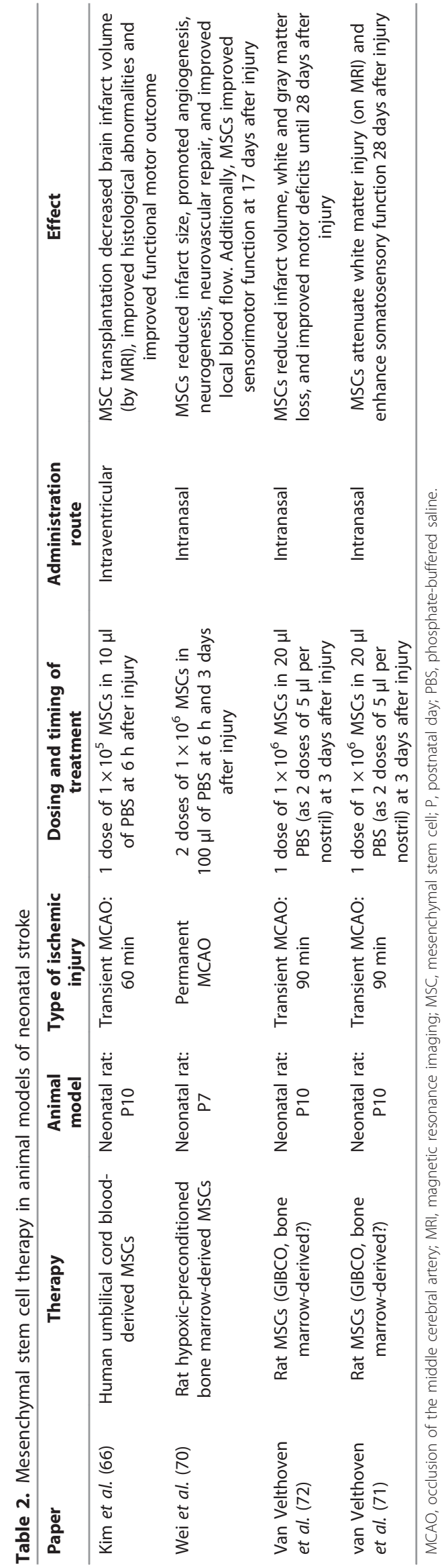

these growth factors were shown to be potentially effective in experimental models of adult stroke, but the therapeutic potential of many of these growth factors still needs to be investigated in experimental neonatal stroke. Although a few reports are available on the beneficial effects of granulocyte colony-stimulating factor (89-91), basic fibroblast growth factor $(92)$ and insulin-like growth factor-I $(93,94)$ in neonatal HI brain injury, evidence is limited to date and therefore beyond the scope of this review.

\section{MSC therapy}

A large meta-analysis from $\mathrm{Vu}$ et al. (95) identified 46 studies that report on the use of MSC treatment in animal models of adult stroke. Of these, 44 reported that MSCs significantly improved neurological outcome. Effect sizes varied significantly with administration route and species and had a median of 0.9 for reduction of infarct volume to 1.8 for Neurological Severity Score. The authors concluded that the effect of MSC therapy was very robust and consistent over different studies, species, routes, and treatment protocols, and translation of MSC treatment in ischemic stroke in (adult) humans should be further enhanced (95).

\section{PROMOTING NEUROREGENERATION IN NEONATAL CLIN- ICAL TRIALS}

\section{Neurotrophic factors}

EPO has been studied most often clinically in the context of neonatal brain injury. Our group recently performed a clinical study in 20 full-term infants with PAIS, who were treated with three doses of recombinant human erythropoietin (rhEPO) $1,000 \mathrm{U} / \mathrm{kg}$ intravenously (96) Most importantly, no adverse effects of rhEPO were observed. Furthermore, volumetric magnetic resonance imaging measurements of the stroke area were smaller in 10 rhEPO-treated infants compared with 10 non-treated PAIS historical controls, but this effect did not reach significance (96). A randomized controlled trial (RCT) from our group is currently undertaken to show the effect of darbepoetin on stroke tissue loss and neurodevelopmental outcome in PAIS patients (ClinicalTrials.gov: NCT03171818). Other groups have described the use of rhEPO or darbepoetin in the context of HIE (97-100). A few RCTs are currently studying full-term infants with perinatal asphyxia who are receiving hypothermia with rhEPO as an add-on therapy and the results are promising $(101,102)$. Most importantly, it was concluded that repeated rhEPO treatment regimens were well tolerated without any serious adverse events (97,99-103).

Currently, there is no evidence from human studies on treatment of PAIS with BDNF, VEGF, or GDNF. However, altered levels of neurotrophic factors (including EPO, VEGF, and BDNF) in serum, cerebrospinal fluid, and/or cord blood have been described for neonates with perinatal asphyxia, hydrocephalus, and intraventricular hemorrhage, which were, in some studies, related to higher severity of brain injury (104-109). Other types of neonatal brain injury, including PAIS, are also very likely to alter the levels of neurotrophic factors in serum as a response to brain damage, but this 


\section{Neuroregeneration after neonatal stroke $\quad$ ReView}

remains to be studied. Studies in adult humans have also found correlations between neurotrophic factors and progenitor cells in serum and severity and outcome of ischemic stroke $(110,111)$, suggesting that neurotrophic factors may serve as predictive parameters in clinical care. This also seems a potential field of interest when setting up future studies in neonatal stroke.

\section{MSC therapy}

At present, no results are available of clinical trials on the treatment of neonatal stroke with MSCs. There is only one clinical trial describing the use of MSCs in treatment of neonates (112). Chang et al. (112) showed in a phase I doseescalation trial the safety and feasibility of intratracheal administration of allogeneic umbilical cord-derived MSCs in nine preterm infants with high risk for bronchopulmonary dysplasia compared with historical case-matched controls. Importantly, no serious adverse events or toxicity related to a higher dose were observed in this study. The same study group is currently performing a phase I study in preterm neonates with severe intraventricular hemorrhage using intracerebroventricularly administered umbilical cordderived MSCs (ClinicalTrials.gov: NCT02274428).

In addition, the group of Cotten et al. (113) has treated neonates with HIE with autologous umbilical cord blood cells, and first results are promising as no safety concerns were observed. Although the exact cell types in the cord blood were not specified, it is hypothesized that cord blood contains MSCs among other progenitor cells (114).

A large meta-analysis reported on a total of 1,012 adult and pediatric patients with various pathological conditions, including ischemic stroke, who were treated with either autologous or allogeneic MSCs and did not show any evidence for severe adverse effects due to MSC transplantation (115). Including eight RCTs, the only significant side effect was an increased risk of transient fever after MSC administration compared with the control group (115). We hypothesize that systemic complications such as fever are probably more common when MSCs are administered systemically (e.g., intravenously) in comparison to local applications.

\section{CLINICAL TRIALS IN ADULT STROKE}

In adult humans, several groups studied EPO as a treatment strategy for acute ischemic stroke; however, results are conflicting (116-118). Treatment with other neurotrophic factors has not been studied for adult stroke yet. A Cochrane review on stem cell transplantation for adult ischemic stroke identified three very small published RCTs, of which two only reported subgroups of patients $(119,120)$. Currently, more clinical trials studying efficacy and safety of MSCs for ischemic stroke are on their way, and safety reports until now are reassuring (121). Results from adult stroke studies may provide supportive evidence for the feasibility and safety of interventions for PAIS. However, as described above, we feel that results from adult trials cannot be directly translated to neonatal care and detailed information on regenerative medicine for adult ischemic stroke therefore goes beyond the scope of this review.

\section{FUTURE PERSPECTIVE}

Current data indicate that MSCs may improve neurological outcome after neonatal stroke by secretion of several growth and/or neurotrophic factors that boost neuroregenerative processes. However, as only few study groups have focused specifically on neonatal stroke (as opposed to HIE), replication of preclinical study results seems mandatory. These studies should mainly focus on optimizing dosing regimens and finding the optimal time window and route of administration for regenerative treatment after neonatal stroke. When these experimental results become available, clinical trials should first address safety issues regarding the use of neurotrophic factors and/or MSCs in neonatal stroke specifically. With respect to rhEPO, these steps have already been undertaken, and our current RCT will show the potential effect of erythropoiesisstimulating agents on stroke recovery in newborns in the near future (ClinicalTrials.gov: NCT03171818).

Most recently, research has focused on combining MSC therapy with additional neurotrophic factors by administration of MSCs that overexpress a neurotrophic factor. For example, BDNF-overexpressing MSCs were intranasally administered to newborn rats with transient MCAO and were found to potently reduce infarct volume, white and gray matter loss, and improve motor deficits compared with vehicle-treated rats (72). Even though BDNF-overexpressing MSCs were not significantly better than 'normal' MSCs in improving neonatal stroke injury in this study, additional experiments are required to further elucidate the possible additional benefits of MSCs transduced with neurotrophic factors. Results of studies assessing the effects of modified MSCs in other animal models of, e.g., adult stroke or neonatal HI may serve as an example for future preclinical testing in neonatal stroke (Table 3). For instance, in an adult acute ischemic stroke model administration of MSCs transduced with the EPO gene decreased infarct volume and improved neurological function to a significant larger extent when compared with treatment with either vehicle, normal MSCs, or a combination of MSCs+rhEPO (122). Another rodent study showed that treatment with GDNF-modified MSCs for adult stroke was effective in reducing apoptotic cell numbers and improving functional outcome more potently than normal MSCs (123). In line, other studies have shown that administration of VEGF-overexpressing NSCs improved functional outcome after HI brain injury in neonatal rats significantly more than normal NSCs $(47,124)$. We hypothesize that future MSC therapy for neonatal brain injury may be improved by manipulating these cells to produce enhanced levels of growth factors or by combining administration of several types of MSCs with specific neurotrophic factors. For example, it was shown that combining NSC transplantation with exogenous BDNF administration improved the nervous function recovery after $\mathrm{HI}$ injury in neonatal rats more than NSCs alone (125). As opposed, Ahn et al. (126) demonstrated 
Table 3. Modified stem cells in animal models of stroke

Paper Stem cells Animal Type of ischemic injury Dosing and timing of treatment Administration route

Ahn et al. (126)

MSCs+BDNF

\section{Neonatal rat:}

P4

Intraventricular
hemorrhage
1 dose of $1 \times 10^{5}$ MSCs at 2 days
after injury

Wang et al.

BDNF+NSCS

Neonatal rat:

P1

Hypoxic-ischemic injury: carotid ligation+hypoxia

Unknown dose ${ }^{a}$ at 7 days after injury

Velthoven

et al. (72)

BDNF-overexpressing

MSCS

$$
\text { P10 }
$$

Transient MCAO: $90 \mathrm{~min}$

Adult rat

Transient MCAO: $120 \mathrm{~min}$

1 dose of $6 \times 10^{5} \mathrm{EPO}-\mathrm{MSC}$ in $5 \mu \mathrm{H}$ at 2 weeks after injury
Zheng et al.
(47)
VEGF-transfected
NSCs
Neonatal rat:
P7
Hypoxic-ischemic injury: carotid ligation+hypoxia
dose of $1 \times 10^{5}$ NSCs in $2 \mu \mathrm{l}$ buffer
Yao et al. (124)
VEGF-transfected
NSCs
Neonatal rat: Hypoxic-ischemic injury:
P7
carotid ligation+hypoxia
at 3 days after injury
1 dose of $1 \times 10^{5}$ NSCs in $2 \mu \mathrm{l}$ buffer
at 3 days after injury

Intraventricular

Intracerebral? ${ }^{\mathrm{a}}$

dose of $1 \times 10^{6}$ MSCs in $20 \mu \mathrm{l} \mathrm{PBS}$ 2 doses of $5 \mu$ l per nostril) at

$$
3 \text { days after injury }
$$

Wang et al.

GDNF-modified

MSCs
Adult rat
Intracerebral (intraparenchymal)

Intracerebral (intraparenchymal)

Intracerebral (intraparenchymal)
Intravenous
Transient MCAO: $120 \mathrm{~min} \quad 1$ dose of $500 \mu \mathrm{l}$ of MSC-suspension $\left(5 \times 10^{6} \mathrm{cells} / \mathrm{ml}\right)$ with or without GDNF-gene expression vector at

After BDNF knockdown, MSCs were no longer effective. BDNF has a pivotal role in MSC working mechanism

BDNF stimulated survival of NSCs. BDNF stimulated proliferation and differentiation of NSCs. Functional recovery was also more improved with BDNF at 4 weeks after inju

BDNF-overexpressing MSCs reduced infarct volume, white and gray matter loss, and improved motor deficits. However BDNFoverexpressing MSCs were not significantly better than normal MSCs at 28 days after injury

MSCs transduced with the EPO gene decreased infarct volume and improved neurological function at 20-35 days, even to a larger extent than normal MSCS

VEGF-overexpressing NSCs improved functional outcome more than NSCs alone

VEGF-overexpressing NSCs improved

histopathological changes of $\mathrm{HI}$ and improved learning and memory abilities more than unmodified NSCs $72 \mathrm{~h}$ after injury

MSC and GDNF-modified MSCs both improved behavioral data after three days. At 14 days after injury, GDNF-modified MSCs were more effective in reducing apoptotic cells than normal MSCs

BDNF, brain-derived neurotrophic factor; EPO, erythropoietin; GDNF, glial-derived neurotrophic factor; HI, hypoxia-ischemia; MCAO, occlusion of the middle cerebral artery; MSC, mesenchymal stem cell; NSC, neural stem cell; P, postnatal day; PBS, phosphate-buffered saline; VEGF, vascular endothelial growth factor.

aFull-text only available in Chinese. 


\section{Neuroregeneration after neonatal stroke ReView}

that MSC therapy in combination with knockdown of BDNF was ineffective in improving outcome after intraventricular hemorrhage in neonatal rats, indicating that BDNF has a pivotal role in MSC therapy for neonatal brain injury. The interplay between several neurotrophic factors, MSCs, or the manipulation of MSCs to stimulate neurotrophic factor production needs to be further elucidated in preclinical studies to optimize regenerative treatment strategies for neonatal brain injury.

\section{CONCLUSION}

In conclusion, owing to their neuroregenerative properties, growth factors and stem cells have a relative large therapeutic window, making them excellent candidates for novel treatment strategies to improve neurological prospects and quality of life of infants with PAIS.

Although experimental neonatal stroke studies and first clinical trials show clear benefits, large promising potential, and safety of therapies using, e.g., VEGF, (rh)EPO, or MSCs, their effectiveness in neonatal PAIS needs to be confirmed. The current hypothesis is that MSCs can improve neurological outcome after neonatal stroke by functioning as miniature factories secreting a wide array of growth and/or neurotrophic factors that boost neuroregenerative processes. Recent studies indicate that modification of MSCs, e.g., by overexpression of specific neurotrophic factors might be even more beneficial to treat neonatal brain injury. More research is needed to determine the safety, therapeutic window, and dosage of modified MSCs and to compare the potential of overexpression of the specific growth factors. An important issue for optimization of MSC-based repair treatments is to determine the potential of overexpression of one specific growth factor vs. combinations of growth factors or even combinations of different overexpressing MSCs at different times after the insult for effective tailor-made treatment of neonatal stroke to eventually combat the devastating consequences of PAIS.

\section{ACKNOWLEDGMENTS}

We are grateful to Nelleke van der Weerd for her extensive literature search.

Disclosure: This study was supported by the Netherlands Organisation for Health Research and Development (ZonMW), the Netherlands (TAS Research Grant 11600200). The authors declare no conflict of interest.

\section{REFERENCES}

1. Kirton A, DeVeber G. Paediatric stroke: pressing issues and promising directions. Lancet Neurol 2015;14:92-102.

2. Agrawal N, Johnston SC, Wu YW, Sidney S, Fullerton HJ. Imaging data reveal a higher pediatric stroke incidence than prior us estimates. Stroke 2009;40:3415-21.

3. Kirton A, Armstrong-Wells J, Chang T, et al. Symptomatic neonatal arterial ischemic stroke: the International Pediatric Stroke Study. Pediatrics 2011;128:e1402-10.

4. Van der Aa N, Benders M, Groenendaal F, de Vries L. Neonatal stroke: a review of the current evidence on epidemiology, pathogenesis, diagnostics and therapeutic options. Acta Paediatr 2014;103:356-64.
5. Fernández-López D, Natarajan N, Ashwal S, Vexler ZS. Mechanisms of perinatal arterial ischemic stroke. J Cereb Blood Flow Metab 2014;34: 921-32.

6. Martinez-Biarge M, Cheong JLY, Diez-Sebastian J, Mercuri E, Dubowitz LMS, Cowan FM. Risk factors for neonatal arterial ischemic stroke: the importance of the intrapartum period. J Pediatr 2016;173:62-8.e1.

7. Tagin $M$ a, Woolcott CG, Vincer MJ, Whyte RK, Stinson DA. Hypothermia for neonatal hypoxic ischemic encephalopathy: an updated systematic review and meta-analysis. Arch Pediatr Adolesc Med 2012;166:558-66.

8. Gunn AJ, Gunn TR. The "pharmacology" of neuronal rescue with cerebral hypothermia. Early Hum Dev 1998;53:19-35.

9. Fan X, Kavelaars A, Heijnen CJ, Groenendaal F, van Bel F. Pharmacological neuroprotection after perinatal hypoxic-ischemic brain injury. Curr Neuropharmacol 2010;8:324-34.

10. Donega V, van Velthoven CTJ, Nijboer CH, Kavelaars A, Heijnen CJ. The endogenous regenerative capacity of the damaged newborn brain: boosting neurogenesis with mesenchymal stem cell treatment. J Cereb Blood Flow Metab 2013;33:625-34.

11. Kadam SD, Mulholland JD, Smith DR, Johnston MV, Comi AM. Chronic brain injury and behavioral impairments in a mouse model of term neonatal strokes. Behav Brain Res 2009;197:77-83.

12. Larpthaveesarp A, Ferriero D, Gonzalez F. Growth factors for the treatment of ischemic brain injury (growth factor treatment). Brain Sci 2015;5:165-77.

13. Rice JE, Vannucci RC, Brierley JB. The influence of immaturity on hypoxic-ischemic brain damage in the rat. Ann Neurol 1981;9:131-41.

14. Vannucci RC. Experimental models of perinatal hypoxic-ischemic brain damage. APMIS Suppl 1993;40:89-95.

15. Tsuji M, Ohshima M, Taguchi A, Kasahara Y, Ikeda T, Matsuyama T. A novel reproducible model of neonatal stroke in mice: comparison with a hypoxia-ischemia model. Exp Neurol 2013;247:218-25.

16. Williamson P, Griffiths G, Norfolk D, Levene M. Blood transfusions and human recombinant erythropoietin in premature newborn infants. Arch Dis Child Fetal Neonatal Ed 1996;75:F65-8.

17. Ohlsson A, Aher SM. Early erythropoietin for preventing red blood cell transfusion in preterm and/or low birth weight infants. Cochrane Database Syst Rev 2006: CD004863.

18. Juul SE, Pet GC. Erythropoietin and neonatal neuroprotection. Clin Perinatol 2015;42:469-81.

19. Yu X, Shacka JJ, Eells JB, et al. Erythropoietin receptor signalling is required for normal brain development. Development 2002;129:505-16.

20. Lu J, Jiang L, Zhu H, Zhang L, Wang T. Hypoxia-inducible factor-1 $\alpha$ and erythropoietin expression in the hippocampus of neonatal rats following hypoxia-ischemia. J Nanosci Nanotechnol 2014;14:5614-9.

21. Bernaudin $\mathrm{M}$, Marti $\mathrm{HH}$, Roussel $\mathrm{S}$, et al. A potential role for erythropoietin in focal permanent cerebral ischemia in mice. J Cereb Blood Flow Metab 1999;19:643-51.

22. Chong ZZ, Kang JQ, Maiese K. Erythropoietin fosters both intrinsic and extrinsic neuronal protection through modulation of microglia, Akt1, Bad, and caspase-mediated pathways. Br J Pharmacol 2003;138:1107-18.

23. Shingo T, Sorokan ST, Shimazaki T, Weiss S. Erythropoietin regulates the in vitro and in vivo production of neuronal progenitors by mammalian forebrain neural stem cells. J Neurosci 2001;21:9733-43.

24. Wang L, Zhang Z, Wang Y, Zhang R, Chopp M. Treatment of stroke with erythropoietin enhances neurogenesis and angiogenesis and improves neurological function in rats. Stroke 2004;35:1732-7.

25. Osredkar D, Sall JW, Bickler PE, Ferriero DM. Erythropoietin promotes hippocampal neurogenesis in in vitro models of neonatal stroke. Neurobiol Dis 2010;38:259-65.

26. Sola A, Wen T-C, Hamrick SEG, Ferriero DM. Potential for protection and repair following injury to the developing brain: a role for erythropoietin? Pediatr Res 2005;57:110R-7R.

27. Gonzalez FF, McQuillen P, Mu D, et al. Erythropoietin enhances longterm neuroprotection and neurogenesis in neonatal stroke. Dev Neurosci 2007;29:321-30. 
28. Gonzalez FF, Abel R, Almli CR, Mu D, Wendland M, Ferriero DM. Erythropoietin sustains cognitive function and brain volume after neonatal stroke. Dev Neurosci 2009;31:403-11.

29. Chang YS, Mu D, Wendland $\mathrm{M}$, et al. Erythropoietin improves functional and histological outcome in neonatal stroke. Pediatr Res 2005;58:106-11.

30. Van der Kooij MA, Groenendaal F, Kavelaars A, Heijnen CJ, van Bel F. Neuroprotective properties and mechanisms of erythropoietin in in vitro and in vivo experimental models for hypoxia/ischemia. Brain Res Rev 2008;59:22-33.

31. Larpthaveesarp A, Georgevits M, Ferriero DM, Gonzalez FF. Delayed erythropoietin therapy improves histological and behavioral outcomes after transient neonatal stroke. Neurobiol Dis 2016;93:57-63.

32. Gonzalez FF, Larpthaveesarp A, McQuillen P, et al. Erythropoietin increases neurogenesis and oligodendrogliosis of subventricular zone precursor cells after neonatal stroke. Stroke 2013;44:753-8.

33. Binder DK, Scharfman HE. Brain-derived neurotrophic factor. Growth Factors 2004;22:123-31.

34. Zhao C, Deng W, Gage FH. Mechanisms and functional implications of adult neurogenesis. Cell 2008;132:645-60.

35. Schäbitz WR, Schwab S, Spranger M, Hacke W. Intraventricular brainderived neurotrophic factor reduces infarct size after focal cerebral ischemia in rats. J Cereb Blood Flow Metab 1997;17:500-6.

36. Diaz J, Abiola S, Kim N, et al. Therapeutic hypothermia provides variable protection against behavioral deficits after neonatal hypoxiaischemia: a potential role for brain-derived neurotrophic factor. Dev Neurosci 2017;39:257-72.

37. Wang Y, Cao M, Liu A, et al. Changes of inflammatory cytokines and neurotrophins emphasized their roles in hypoxic-ischemic brain damage. Int J Neurosci 2013;123:191-5.

38. Huang W, Meng F, Cao J, Liu X, Zhang J, Li M. Neuroprotective role of exogenous brain-derived neurotrophic factor in hypoxia-hypoglycemiainduced hippocampal neuron injury via regulating Trkb/MiR134 signaling. J Mol Neurosci 2017: 134.

39. Deumens R, Koopmans GC, Jaken RJP, et al. Stimulation of neurite outgrowth on neonatal cerebral astrocytes is enhanced in the presence of BDNF. Neurosci Lett 2006;407:268-73.

40. Dixon KJ, Sherrard RM. Brain-derived neurotrophic factor induces postlesion transcommissural growth of olivary axons that develop normal climbing fibers on mature Purkinje cells. Exp Neurol 2006;202:44-56.

41. Morcuende S, Muñoz-Hernández R, Benítez-Temiño B, Pastor AM, de la Cruz RR. Neuroprotective effects of NGF, BDNF, NT-3 and GDNF on axotomized extraocular motoneurons in neonatal rats. Neuroscience 2013;250:31-48.

42. Husson I, Rangon CM, Lelièvre V, et al. BDNF-induced white matter neuroprotection and stage-dependent neuronal survival following a neonatal excitotoxic challenge. Cereb Cortex 2005;15:250-61.

43. Sentilhes L, Michel C, Lecourtois M, et al. Vascular endothelial growth factor and its high-affinity receptor (VEGFR-2) are highly expressed in the human forebrain and cerebellum during development. J Neuropathol Exp Neurol 2010;69:111-28.

44. Zhang L, Qu Y, Yang C, et al. Signaling pathway involved in hypoxiainducible factor-1alpha regulation in hypoxic-ischemic cortical neurons in vitro. Neurosci Lett 2009;461:1-6.

45. Lafuente JV, Ortuzar N, Bengoetxea H, Bulnes S, Argandoña EG. Vascular endothelial growth factor and other angioglioneurins. Key molecules in brain development and restoration. Int Rev Neurobiol 2012;102:317-46.

46. Greenberg DA, Jin K. From angiogenesis to neuropathology. Nature 2005;438:954-9.

47. Zheng XR, Zhang SS, Yin F, et al. Neuroprotection of VEGF-expression neural stem cells in neonatal cerebral palsy rats. Behav Brain Res 2012;230:108-15.

48. Mu D, Jiang X, Sheldon RA, et al. Regulation of hypoxia-inducible factor lalpha and induction of vascular endothelial growth factor in a rat neonatal stroke model. Neurobiol Dis 2003;14:524-34.
49. Sun J, Zhou W, Sha B, Yang Y. Ischemia induced neural stem cell proliferation and differentiation in neonatal rat involved vascular endothelial growth factor and transforming growth factor-beta pathways. Brain Dev 2010;32:191-200.

50. Shimotake J, Derugin N, Wendland M, Vexler ZS, Ferriero DM. Vascular endothelial growth factor receptor-2 inhibition promotes cell death and limits endothelial cell proliferation in a neonatal rodent model of stroke. Stroke 2010;41:343-9.

51. Dzietko M, Derugin N, Wendland MF, Vexler ZS, Ferriero DM. Delayed VEGF treatment enhances angiogenesis and recovery after neonatal focal rodent stroke. Transl Stroke Res 2013;4:189-200.

52. Zhang ZG, Zhang L, Jiang Q, et al. VEGF enhances angiogenesis and promotes blood-brain barrier leakage in the ischemic brain. J Clin Invest 2000;106:829-38.

53. Zheng XR, Zhang SS, Yang YJ, et al. Adenoviral vector-mediated transduction of VEGF improves neural functional recovery after hypoxia-ischemic brain damage in neonatal rats. Brain Res Bull 2010;81: $372-7$.

54. Feng Y, Rhodes PG, Bhatt AJ. Neuroprotective effects of vascular endothelial growth factor following hypoxic ischemic brain injury in neonatal rats. Pediatr Res 2008;64:370-4.

55. Lin L, Doherty D, Lile J, Bektesh S, Collins F. GDNF: a glial cell linederived neurotrophic factor for midbrain dopaminergic neurons. Science 1993;260:1130-2.

56. Junger H, Varon S. Neurotrophin-4 (NT-4) and glial cell line-derived neurotrophic factor (GDNF) promote the survival of corticospinal motor neurons of neonatal rats in vitro. Brain Res 1997;762:56-60.

57. Li L, Wu W, Lin LF, Lei M, Oppenheim RW, Houenou LJ. Rescue of adult mouse motoneurons from injury-induced cell death by glial cell line-derived neurotrophic factor. Proc Natl Acad Sci USA 1995;92: 9771-5.

58. Beck KD, Valverde J, Alexi T, et al. Mesencephalic dopaminergic neurons protected by GDNF from axotomy-induced degeneration in the adult brain. Nature 1995;373:339-41.

59. Li S-J, Liu W, Wang J-L, et al. The role of TNF- $\alpha$, IL-6, IL-10, and GDNF in neuronal apoptosis in neonatal rat with hypoxic-ischemic encephalopathy. Eur Rev Med Pharmacol Sci 2014;18:905-9.

60. Matheson CR, Carnahan J, Urich JL, Bocangel D, Zhang TJ, Yan Q. Glial cell line-derived neurotrophic factor (GDNF) is a neurotrophic factor for sensory neurons: comparison with the effects of the neurotrophins. J Neurobiol 1997;32:22-32.

61. Zhang WR, Hayashi T, Iwai M, et al. Time dependent amelioration against ischemic brain damage by glial cell line-derived neurotrophic factor after transient middle cerebral artery occlusion in rat. Brain Res 2001;903:253-6.

62. Chen B, Gao X-Q, Yang C-X, et al. Neuroprotective effect of grafting GDNF gene-modified neural stem cells on cerebral ischemia in rats. Brain Res 2009;1284:1-11.

63. Dezawa M, Kanno H, Hoshino M, et al. Specific induction of neuronal cells from bone marrow stromal cells and application for autologous transplantation. J Clin Invest 2004;113:1701-10.

64. Uccelli A, Moretta L, Pistoia V. Mesenchymal stem cells in health and disease. Nat Rev Immunol 2008;8:726-36.

65. Dominici M, Le Blanc K, Mueller I, et al. Minimal criteria for defining multipotent mesenchymal stromal cells. The International Society for Cellular Therapy position statement. Cytotherapy 2006;8:315-7.

66. Kim ES, Ahn SY, Im GH, et al. Human umbilical cord blood-derived mesenchymal stem cell transplantation attenuates severe brain injury by permanent middle cerebral artery occlusion in newborn rats. Pediatr Res 2012;72:277-84.

67. Danielyan L, Schäfer R, von Ameln-Mayerhofer A, et al. Intranasal delivery of cells to the brain. Eur J Cell Biol 2009;88:315-24.

68. Wei N, Yu SP, Gu X, et al. Delayed intranasal delivery of hypoxicpreconditioned bone marrow mesenchymal stem cells enhanced cell homing and therapeutic benefits after ischemic stroke in mice. Cell Transplant 2013;22:977-91. 
69. Donega V, Nijboer CH, van Tilborg G, Dijkhuizen RM, Kavelaars A, Heijnen CJ. Intranasally administered mesenchymal stem cells promote a regenerative niche for repair of neonatal ischemic brain injury. Exp Neurol 2014;261:53-64.

70. Wei ZZ, Gu X, Ferdinand A, et al. Intranasal delivery of bone marrow mesenchymal stem cells improved neurovascular regeneration and rescued neuropsychiatric deficits after neonatal stroke in rats. Cell Transplant 2015: 1-40.

71. Van Velthoven CT, Dzietko M, Wendland MF, et al. Mesenchymal stem cells attenuate MRI-identifiable injury, protect white matter, and improve long-term functional outcomes after neonatal focal stroke in rats. J Neurosci Res 2017;95:1225-36.

72. Van Velthoven CTJ, Sheldon RA, Kavelaars A, et al. Mesenchymal stem cell transplantation attenuates brain injury after neonatal stroke. Stroke 2013;44:1426-32.

73. Van Velthoven CTJ, Kavelaars A, van Bel F, Heijnen CJ. Mesenchymal stem cell transplantation changes the gene expression profile of the neonatal ischemic brain. Brain Behav Immun 2011;25:1342-8.

74. Kamei N, Tanaka N, Oishi Y, et al. Bone marrow stromal cells promoting corticospinal axon growth through the release of humoral factors in organotypic cocultures in neonatal rats. J Neurosurg Spine 2007;6:412-9.

75. Van Velthoven CTJ, Kavelaars A, van Bel F, Heijnen CJ. Nasal administration of stem cells: a promising novel route to treat neonatal ischemic brain damage. Pediatr Res 2010;68:419-22.

76. Bower AJ. Plasticity in the adult and neonatal central nervous system. $\mathrm{Br}$ J Neurosurg 1990;4:253-64.

77. Schneider GE. Mechanisms of functional recovery following lesions of visual cortex or superior colliculus in neonate and adult hamsters. Brain Behav Evol 1970;3:295-323.

78. Titomanlio L, Kavelaars A, Dalous J, et al. Stem cell therapy for neonatal brain injury: perspectives and challenges. Ann Neurol 2011;70: 698-712.

79. Bondolfi L, Ermini F, Long JM, Ingram DK, Jucker M. Impact of age and caloric restriction on neurogenesis in the dentate gyrus of $\mathrm{C} 57 \mathrm{BL} / 6$ mice. Neurobiol Aging 2004;25:333-40.

80. Kuhn HG, Dickinson-Anson H, Gage FH. Neurogenesis in the dentate gyrus of the adult rat: age-related decrease of neuronal progenitor proliferation. J Neurosci 1996;16:2027-33.

81. Leuner B, Kozorovitskiy Y, Gross CG, Gould E. Diminished adult neurogenesis in the marmoset brain precedes old age. Proc Natl Acad Sci USA 2007;104:17169-73.

82. Comi A, Johnston MStroke: neonate vs. adultIn:. Handbook of the Neuroscience of Aging. Elsevier, 2009 pp 491-4.

83. Takeshima $Y$, Nakamura M, Miyake H, et al. Neuroprotection with intraventricular brain-derived neurotrophic factor in rat venous occlusion model. Neurosurgery 2011;68:1334-41.

84. Schäbitz WR, Sommer C, Zoder W, Kiessling M, Schwaninger M, Schwab S. Intravenous brain-derived neurotrophic factor reduces infarct size and counterregulates Bax and Bcl-2 expression after temporary focal cerebral ischemia. Stroke 2000;31:2212-7.

85. Zhang A, Liang L, Niu H, Xu P, Hao Y. Protective effects of VEGF treatment on focal cerebral ischemia in rats. Mol Med Rep 2012;6: 1315-8.

86. Kitagawa H, Hayashi T, Mitsumoto Y, Koga N, Itoyama Y, Abe K. Reduction of ischemic brain injury by topical application of glial cell line-derived neurotrophic factor after permanent middle cerebral artery occlusion in rats. Stroke 1998;29:1417-22.

87. Minnerup J, Heidrich J, Rogalewski A, Schäbitz WR, Wellmann J. The efficacy of erythropoietin and its analogues in animal stroke models: a meta-analysis. Stroke 2009;40:3113-20.

88. Lanfranconi S, Locatelli F, Corti S, et al. Growth factors in ischemic stroke. J Cell Mol Med 2011;15:1645-87.

89. Neubauer V, Wegleiter K, Posod A, et al. Delayed application of the haematopoietic growth factors G-CSF/SCF and FL reduces neonatal excitotoxic brain injury. Brain Res 2016;1634:94-103.
90. Li L, Klebe D, Doycheva D, et al. G-CSF ameliorates neuronal apoptosis through GSK-3 $\beta$ inhibition in neonatal hypoxia-ischemia in rats. Exp Neurol 2015;263:141-9.

91. Kim BR, Shim JW, Sung DK, et al. Granulocyte stimulating factor attenuates hypoxic-ischemic brain injury by inhibiting apoptosis in neonatal rats. Yonsei Med J 2008;49:836-42.

92. Kirschner PB, Henshaw R, Weise J, et al. Basic fibroblast growth factor protects against excitotoxicity and chemical hypoxia in both neonatal and adult rats. J Cereb Blood Flow Metab 1995;15:619-23.

93. Wood TL, Loladze V, Altieri S, et al. Delayed IGF-1 administration rescues oligodendrocyte progenitors from glutamate-induced cell death and hypoxic-ischemic brain damage. Dev Neurosci 2007;29:302-10.

94. Lin S, Fan L, Rhodes PG, Cai Z. Intranasal administration of IGF-1 attenuates hypoxic-ischemic brain injury in neonatal rats. Exp Neurol 2009;217:361-70.

95. Vu Q, Xie K, Eckert M, Zhao W, Cramer SC. Meta-analysis of preclinical studies of mesenchymal stromal cells for ischemic stroke. Neurology 2014;82:1277-86.

96. Benders MJ, van der Aa NE, Roks M, et al. Feasibility and safety of erythropoietin for neuroprotection after perinatal arterial ischemic stroke. J Pediatr 2014;164:481-6.e1-2.

97. Elmahdy H, El-Mashad A-R, El-Bahrawy H, El-Gohary T, El-Barbary A, Aly H. Human recombinant erythropoietin in asphyxia neonatorum: pilot trial. Pediatrics 2010;125:e1135-42.

98. Baserga MC, Beachy JC, Roberts JK, et al. Darbepoetin Administration to Neonates Undergoing Cooling for Encephalopathy (DANCE): a safety and pharmacokinetic trial. Pediatr Res 2015: 3-10.

99. Wu YW, Bauer LA, Ballard RA, et al. Erythropoietin for neuroprotection in neonatal encephalopathy: safety and pharmacokinetics. Pediatrics 2012;130:683-91.

100. Rogers EE, Bonifacio SL, Glass HC, et al. Erythropoietin and hypothermia for hypoxic-ischemic encephalopathy. Pediatr Neurol 2014;51:657-62.

101. Zhu C, Kang W, Xu F, et al. Erythropoietin improved neurologic outcomes in newborns with hypoxic-ischemic encephalopathy. Pediatrics 2009;124:e218-26.

102. Wu YW, Mathur AM, Chang T, et al. High-dose erythropoietin and hypothermia for hypoxic-ischemic encephalopathy: a phase II trial. Pediatrics 2016;137https//doi.org/10.152/peds.2016-0191.

103. Mulkey SB, Ramakrishnaiah RH, McKinstry RC, et al. Erythropoietin and brain magnetic resonance imaging findings in hypoxic-ischemic encephalopathy: volume of acute brain injury and 1-year neurodevelopmental outcome. J Pediatr 2017: 3-6.

104. El Shimi MS, Hassanein SMA, Mohamed MH, et al. Predictive value of vascular endothelial growth factor in preterm neonates with intraventricular haemorrhage. J Matern Fetal Neonatal Med 2012;25:1586-90.

105. Koehne P, Hochhaus F, Felderhoff-Mueser U, Ring-Mrozik E, Obladen M, Bührer C. Vascular endothelial growth factor and erythropoietin concentrations in cerebrospinal fluid of children with hydrocephalus. Childs Nerv Syst 2002;18:137-41.

106. Imam SS, Gad GI, Atef SH, Shawky MA. Cord blood brain derived neurotrophic factor: diagnostic and prognostic marker in fullterm newborns with perinatal asphyxia. Pak J Biol Sci 2009;12:1498-504.

107. Aly H, Hassanein S, Nada A, Mohamed MH, Atef SH, Atiea W. Vascular endothelial growth factor in neonates with perinatal asphyxia. Brain Dev 2009;31:600-4.

108. Chalak LF, Sánchez PJ, Adams-Huet B, Laptook AR, Heyne RJ, Rosenfeld CR. Biomarkers for severity of neonatal hypoxic-ischemic encephalopathy and outcomes in newborns receiving hypothermia therapy. J Pediatr 2014: 164.

109. Sweetman DU, Onwuneme C, Watson WR, Murphy JFA, Molloy EJ. Perinatal asphyxia and erythropoietin and VEGF: serial serum and cerebrospinal fluid responses. Neonatology 2017: 253-9.

110. Stanne TM, Aberg ND, Nilsson S, et al. Low circulating acute brain-derived neurotrophic factor levels are associated with poor long-term functional outcome after ischemic stroke. Stroke 2016;47: 1943-5. 
111. Chen Y, Lu B, Wang J, et al. Circulating CD133+ CD34+ progenitor cells and plasma stromal-derived factor-1alpha: predictive role in ischemic stroke patients. J Stroke Cerebrovasc Dis 2015;24:319-26.

112. Chang YS, Ahn SY, Yoo HS, et al. Mesenchymal stem cells for bronchopulmonary dysplasia: phase 1 dose-escalation clinical trial. J Pediatr 2014;164:966-72.e6.

113. Cotten CM, Murtha AP, Goldberg RN, et al. Feasibility of autologous cord blood cells for infants with hypoxic-ischemic encephalopathy. J Pediatr 2014;164:973.e1-9.e1.

114. Verina T, Fatemi A, Johnston MV, Comi AM. Pluripotent possibilities: human umbilical cord blood cell treatment after neonatal brain injury. Pediatr Neurol 2013;48:346-54.

115. Lalu MM, McIntyre L, Pugliese C, et al. Safety of cell therapy with mesenchymal stromal cells (SafeCell): a systematic review and metaanalysis of clinical trials. PLoS ONE 2012;7:e47559.

116. Tsai T-H, Lu C-H, Wallace CG, et al. Erythropoietin improves long-term neurological outcome in acute ischemic stroke patients: a randomized, prospective, placebo-controlled clinical trial. Crit Care 2015;19:1-9.

117. Ehrenreich H, Hasselblatt M, Dembowski C, et al. Erythropoietin therapy for acute stroke is both safe and beneficial. Mol Med 2002;8:495-505.

118. Ehrenreich H, Weissenborn K, Prange H, et al. Recombinant human erythropoietin in the treatment of acute ischemic stroke. Stroke 2009;40: e647-56.

119. Boncoraglio GB, Bersano A, Candelise L, Reynolds BA, Parati EA. Stem cell transplantation for ischemic stroke. Cochrane Database Syst Rev 2010: CD007231.

120. Kondziolka D, Steinberg GK, Wechsler L, et al. Neurotransplantation for patients with subcortical motor stroke: a phase 2 randomized trial. J Neurosurg 2005;103:38-45.
121. Hess DC, Wechsler LR, Clark WM, et al. Safety and efficacy of multipotent adult progenitor cells in acute ischaemic stroke (MASTERS): a randomised, double-blind, placebo-controlled, phase 2 trial. Lancet Neurol 2017;16:360-8.

122. Cho G-W, Koh S-H, Kim M-H, et al. The neuroprotective effect of erythropoietin-transduced human mesenchymal stromal cells in an animal model of ischemic stroke. Brain Res 2010;1353:1-13.

123. Wang Y, Geng T, Ni A, Yin H, Han B. Effects of transplanted GDNF gene modified marrow stromal cells on focal cerebral ischemia in rats. Front Integr Neurosci 2011;5:89.

124. Yao Y, Zheng X, Zhang S, et al. Transplantation of vascular endothelial growth factor-modified neural stem/progenitor cells promotes the recovery of neurological function following hypoxic-ischemic brain damage. Neural Regen Res 2016;11:1456-63.

125. Wang $\mathrm{H}$, Zhu X, Wang L, et al. [Brain-derived neurotrophic factor and neural stem cells transplantation in treatment of hypoxic-ischemic brain injury in rats]. Zhonghua Er Ke Za Zhi 2008;46:544-9.

126. Ahn SY, Chang YS, Sung DK, Sung SI, Ahn J-Y, Park WS. Pivotal role of brain derived neurotrophic factor secreted by mesenchymal stem cells in severe intraventricular hemorrhage in the newborn rats. Cell Transplant 2016;26:145-56.

127. Bemelmans AP, Husson I, Jaquet M, Mallet J, Kosofsky BE, Gressens P. Lentiviral-mediated gene transfer of brain-derived neurotrophic factor is neuroprotective in a mouse model of neonatal excitotoxic challenge. J Neurosci Res 2006;83:50-60.

128. Wen TC, Rogido M, Peng H, Genetta T, Moore J, Sola A. Gender differences in long-term beneficial effects of erythropoietin given after neonatal stroke in postnatal day-7 rats. Neuroscience 2006;139: 803-11. 